\section{\#FOAMed errors: does the opportunity for speedy resolution outweigh the risk of rapid dissemination?}

\author{
Simon Carley ${ }^{0}, 2$, Associate Editor
}

Edwards and Roland report an interesting natural experiment in the role of knowledge dissemination in the era of social media and free open access medical education (\#FOAMed). ${ }^{1}$ In the opinion of many emergency medicine educationalists, \#FOAMed resources are challenging and changing our traditional models of sharing knowledge through publications such as the EMJ. ${ }^{2}$

The paper reports on two inadvertent publication errors on a UK \#FOAMed blog. These were rapidly disseminated through social media to thousands of recipients in a very short space of time. Although the errors were unlikely to result in significant patient harm, the implication is that potentially harmful information might be inadvertently disseminated across a wide audience and with little control from the authors. In other words, the oft-stated advantages of online publication, those of speed, amplification and reach, are also factors that might disseminate incorrect or even harmful content to a much wider audience than traditional publication methods. Information in online formats are far easier to share onwards, either in original or modified form, such that the errors may be compounded and amplified beyond the control of the original authors.

The counterbalance to this is the fact that both errors were spotted far faster than they would have been through a traditional publishing route. Similarly, the required corrections were rapidly created and posted online within hours of being identified. Thus, in \#FOAMedbased education, the risk of rapid dissemination of error is arguably mitigated by the rapid identification and correction of those errors.

${ }^{1}$ Emergency Medicine, Central Manchester and Manchester Children's University Hospitals NHS Trust, Manchester, UK

2Emergency Medicine, Manchester Metropolitan University, All Saints Campus, Manchester, UK

Correspondence to Prof. Simon Carley, Emergency Medicine, Manchester Metropolitan University - All Saints Campus, Manchester M15 6BH, UK; arleys@me.com
Concerns about the quality and control of \#FOAMed-based learning has focused on the risks of early adoption, content bias and dissemination of false information. ${ }^{3}$ These concerns have been addressed by \#FOAMed creators who have argued that the ability of online publishing to react rapidly is a strength rather than a weakness. ${ }^{4}$ What this paper adds is an understanding of just how rapidly knowledge dissemination can occur before it is spotted and corrected.

As consumers of online learning, it is right that we question the quality control processes of blogs and other \#FOAMed materials. There is no doubt that \#FOAMed has a reach and impact that many journals would envy, but without some of the review processes that underpin traditional publishing, it is perhaps inevitable that mistakes will be disseminated.

The adoption of systems of editorial and peer review has increased in recent years, especially on the more influential \#FOAMed sites, and has been identified as a quality metric for blogs and podcasts.

Mistakes are not solely an online problem. Traditional publishing processes, despite established and well-described editorial and peer review processes, frequently contain clinically important errors that are slow to be corrected and difficult to track. ${ }^{5}$ There are established procedures to correct these through 'errata' published both in print, online and with linkage to the original article on databases such as PubMed, but these are not uniformly applied in traditional publishing either. ${ }^{6}$ What we often think of as robust publishing procedures for errata are in reality often slow and incomplete. In addition, the impact of errata in traditional media is difficult to track. In contrast, online learning platforms can track the reach of this information using web-based tools. Indeed, Edwards and Roland could not have performed this study for an article published in a print journal, as they would lack access to the breadth and richness of tracking and engagement data that are available online. Making comparisons between online and traditional publishing mechanisms is therefore difficult, although it is safe to assume that there are risks with both.

Processes to correct, to link and ideally to track errata in the new era of \#FOAMed-disseminated education are variable and are currently left to the discretion of individual websites and authors. 'Learning from mistakes on Social Media' serves as a warning for those clinicians who create educational materials online that they should consider how to develop a more consistent and robust approach to the management of inadvertent publication error.

Edwards and Roland have shown us that errata can be widely and rapidly disseminated, but also that such errors can be rapidly identified and corrected. Whether this represents a situation that is better, worse or simply faster than traditional publishing methods remains uncertain.

\section{Contributors SC is the single author.}

Funding The authors have not declared a specific grant for this research from any funding agency in the public, commercial or not-for-profit sectors.

Competing interests SC is creator, webmaster and chief editor of the St Emlyn's blog and podcast.

Patient consent for publication Not required.

Provenance and peer review Not commissioned; internally peer reviewed.

(c) Author(s) (or their employer(s)) 2019. No commercial re-use. See rights and permissions. Published by BMJ.

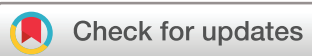

To cite Carley S. Emerg Med J 2019;36:452.

Accepted 3 June 2019

Published Online First 10 July 2019

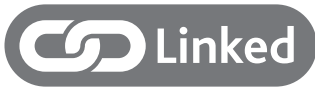

- http://dx.doi.org/10.1136/emermed-2019-208501

Emerg Med J 2019;36:452.

doi:10.1136/emermed-2019-208787

\section{REFERENCES}

1 Edwards S, Roland D. Learning from mistakes on social media. Emerg Med J 2019;36:453-5.

2 Chan T, Trueger NS, Roland D, et al. Evidence-based medicine in the era of social media: scholarly engagement through participation and online interaction. CJEM 2018;20:3-8.

3 Cameron P. Pundit Based Medicine [Internet]. Emergency Physicians International 2015 http://www. epijournal.com/articles/240/pundit-based-medicine.

4 Cameron P, Carley S, Weingart S, et al. CJEM Debate Series: \#SocialMedia—Social media has created emergency medicine celebrities who now influence practice more than published evidence. CJEM 2017;19:471-4.

5 Farrah K, Rabb D. Errata for trial publications are not uncommon, are frequently not trivial, and can be challenging to access: a retrospective review. J Med Libr Assoc 2019;107:187-93.

6 Hauptman PJ, Armbrecht ES, Chibnall JT, et al. Errata in medical publications. Am J Med 2014;127:779-85. 